\title{
EL CURSO DE LITERATURA INFANTIL Y JUVENIL EN LOS PROGRAMAS UNIVERSITARIOS DE EDUCACIÓN
}

\author{
Manuel Vejarano Ingar* \\ Universidad Católica Sedes Sapientiae
}

Resumen: En este trabajo el autor expone acerca de las diversas miradas que provocan la investigación y el estudio de la literatura infantil y juvenil, curso que no es tan simple de enmarcar y trabajar. En una facultad de educación dependerá de qué es lo que se pretende lograr con los futuros maestros. Para ello propone tres líneas de estudio que pueden sostener y dirigir este curso para los futuros docentes: lo literario, la libertad textual, y el cine y la televisión.

Palabras Clave: educación, literatura, literatura infantil, cine, televisión

Aвstract: In this paper, the author explains how studies and research provoke different points of view on nursery and juvenile literature, which are not easy to be framed and worked out. In a faculty of education this will depend on what is to be achieved in teacher students. For this, three study issues are proposed in order to sustain and address the course for the upcoming teachers: literature, textual freedom, movies and television.

KeY wORDs: education, literature, nursery literature, movies, television

* Manuel Vejarano Ingar es Licenciado en Educación y Ciencias Religiosas por la Universidad Marcelino Champagnat. Tiene una Maestría en Literatura Infantil y Animación a la Lectura (Universidad Católica Sedes Sapientiae-UCSS). Es Coordinador del Área de Comunicación y Producción del Lenguaje del pregrado UCSS. Dicta la cátedra de Seminario de Literatura Infantil en la Facultad de Ciencias de la Educación y Humanidades de la UCSS. 
a propuesta de este trabajo nace de la experiencia docente universitaria, en la cual mi principal preocupación desde hace algunos años ha sido la formación literaria de futuros docentes del nivel Inicial y Primaria en el curso de literatura infantil. La investigación ha sido un apoyo constante para alimentar el dictado, pero más aún lo ha sido el diálogo con los mismos estudiantes que ya practican o trabajan en aulas. El poner a prueba lo leído con la práctica de estas docentes que recién comienzan su carrera (muchas de las cuales si bien no practican ya trabajan) es lo que me lleva a direccionar mejor los objetivos y herramientas.

Menciono esto porque me parece que ambas dimensiones, la académica y la práctica, ayudan a dilucidar mejor una discusión que plantearé en este artículo.

En este sentido, la revisión de algunos sílabos de diversas universidades me revela que no estamos mal encaminados. Todos coinciden en la importancia de brindar a los futuros docentes una formación literaria tanto teórica como práctica, pero también se percibe, sutilmente o no, un activismo que, con el propósito loable de entrenar a los docentes en el desarrollo de actividades con textos, puede transformar el curso en un simple taller o en un curso de pura didáctica.

No sorprende. En la práctica me he encontrado con miradas diversas sobre este curso. Una de ellas, por ejemplo, advierte cuando se intenta brindar una abundante bibliografía (de teoría o novelas y cuentos): «No van a ser literatos, van a ser docentes», como si lo uno estuviera reñido con lo otro. Cada vez más, tanto niños como adultos, leemos menos, y eso incluye a los docentes; no obstante, cada vez más leemos «útilmente», «informativamente», «instruccionalmente» antes que «humanamente», es decir, sin considerar aquello que por intuición nos fortalece como hombres y mujeres. 
EL CURSO DE LITERATURA INFANTIL Y JUVENIL

EN LOS PROGRAMAS UNIVERSITARIOS DE EDUCACIÓN

Otra mirada es aquella que desea trasladar el núcleo del curso a la técnica donde, a partir de una mirada únicamente psicológica o pedagógica, se hace del texto una sierva al servicio de las «actividades», que al final terminan siendo la materia del curso. Esto puede llevar al activismo puro y sin sentido donde las «dinámicas» pintan un aparente paisaje de trabajo, pero que en realidad solo hacen «mover» a los alumnos sin que descubran el texto literario como una realidad en la que deben introducirse poco a poco y de forma personal.

Como se dan cuenta el curso de literatura infantil, por las diversas miradas que provoca, no es tan simple de enmarcar y trabajar. En una facultad de ducación dependerá de qué es lo que pretendemos lograr con los futuros maestros. Por ello les propongo aquí tres puntos, tres columnas que, en mi opinión, pueden sostener este curso para los futuros docentes.

\section{LA PRIMERA COLUMNA ES EL RESPETO POR LO LITERARIO}

Olvidamos que el término de Literatura infantil tiene como sustantivo a «literatura» y a «infantil» como adjetivo. En el origen de la literatura infantil descubrimos que la literatura fue sierva de la pedagogía. El cambio, la liberación de lo puramente didáctico por parte de lo literario, fue un proceso moderno que llega y continua hasta nuestros días, la calidad literaria en las obras para niños y jóvenes ha aumentado, pero seguimos pensando que la literatura en la formación docente debe ser instrumento para aprender conocimientos o valores, una visión muy parcial que nos impide reconocer el valor de una verdadera literatura infantil que «[...] cuando se compromete con el interés del niño, se transforma en un medio de acceso a lo real, en la medida en que facilita la ordenación de experiencias existenciales, a través del conocimiento de historias, y la expansión de su dominio lingüístico» (Zilberman 2006: 28). 
Acercar al futuro docente a la teoría literaria no es un capricho de los literatos, tampoco un tema superfluo. Para entender esto pondré como ejemplo a la «animación lectora». Este concepto, que engloba prácticas, técnicas y metodologías para promocionar la presencia del libro en las escuelas y acercar al niño a la lectura ha permitido identificar el rol del docente como un «mediador» que ayuda, anima, mueve al niño a que se acerque a un libro, lo lea y, sobre todo, lo disfrute. Hasta aquí todo suena muy bien, pero, como bien señala Carmen Domech: «De nada serviría un consumo indiscriminado de libros, en muchos casos mediocres, si no se profundizara en sus contenidos y se intentara ir más allá de una lectura superficial». Y es que, como comenta la misma Domech, la idea de la animación implica poder hacer partícipe a los niños y jóvenes de la lectura. En ese caso, un profesor que no tenga formación ni respeto por la literatura ¿cómo los haría participar?, ¿de qué hablaría?, ¿de cuántos personajes había en el relato?, ¿de qué le dijo tal personaje a tal otro?, ¿de qué piensa el alumno de tal acción? Aquí las taxonomías son una ayuda, pero sin la base formativa literaria se convierten solo en una herramienta superficial. Sin esta base, los docentes estaríamos siempre atados a las técnicas, a las preguntas de comprensión que nos entregan junto con los textos. La raíz de esto se halla en un afán, que se concretiza en ciertos lugares de estudio pedagógico, por ir de frente a la práctica pedagógica, desechando las humanidades, tal como ha manifestado Vargas Llosa en una entrevista en Buenos Aires:

Una de las ideas que por desgracia parece prevalecer es la de que esa educación (de los jóvenes) debe ser fundamentalmente pragmática, que debe preparar a los jóvenes sobre todo para asumir la revolución tecnológica de nuestro tiempo sacrificando las humanidades, como si las humanidades fueran un lujo 
EL CURSO DE LITERATURA INFANTIL Y JUVENIL EN LOS PROGRAMAS UNIVERSITARIOS DE EDUCACIÓN

prescindible. En muchos países las reformas de la educación van orientadas en ese sentido. A mí eso me parece gravísimo, porque creo que las humanidades son las que mantienen justamente los denominadores comunes, en tanto que la tecnología y la ciencia tienden a crear especialistas, no puede ser de otra manera, por la elaboración, por la diversificación extraordinaria del conocimiento. ${ }^{1}$

$\mathrm{Y}$ es que hablar de literatura es hablar de arte y de humanidades, hablar de espacios de reflexión, propios e íntimos; es en el centro de cada persona, en sus intereses y mundo interior donde los mundos que la literatura le propone brillan y cobran valor. Si los futuros docentes logran un conocimiento, respeto y acercamiento a la literatura ya han dado un gran paso, lo mismo podrán lograr sus alumnos, el resto estará en manos de su libertad.

\section{LA SEGUNDA COLUMNA ES LA LIBERTAD TEXTUAL}

Contamos hoy con un background cultural; podemos apoyarnos en un canon literario infantil mundial: desde los clásicos cuentos de hadas, con versiones de los Grimm, Perrault y Andersen pasando por el Pinocho de Collodi; hasta llegar a más contemporáneos como Maurice Sendak (con Donde viven los monstruos) o Roald Dahl (con sus conocidas obras Charlie y la fábrica de chocolates, Matilda, Las brujas, etc.). En este camino bibliográfico podemos introducir obras más locales, desde mitos y leyendas que en nuestro país

1 Ver "A los niños no se les puede obligar a leer, "sí sobornar"». Entrevista a Mario Vargas Llosa en $A B C$ color, diario de Paraguay, edición digital, 25 de abril de 2010. Disponible en <www.abc.com.py/articulos/a-los-ninos-no-se-les-puede-obligar-a-leersi-sobornar-249330.html>. Consulta hecha el 22/04/2011. 
abundan (tal como las recogidas por Arguedas e Izquierdo Ríos en su obra Mitos, leyendas y cuentos peruanos), pasando por una selección de tradiciones de Palma hasta los contemporáneos Eslava, Colchado, Tejo, entre otros. Esto solo por mencionar narrativa, no hablo de poesía. En este camino, en compañía de estos y otros autores se descubre lo que señala Parreira:

Si el objetivo del arte literario es divertir, emocionar, dar placer, provocar recuerdos, establecer diálogos, la literatura infantil, más aún, debe ser el lugar donde se valorice el lenguaje y la imaginación, dejando de lado lo que es objetivo científico, para trabajar con la contradicción y el extrañamiento. Eso no significa, de ningún modo, un texto caótico e incoherente, porque la literatura tiene una lógica interna [...] La función de la literatura será rebelarse y usar creativamente el lenguaje proporcionando placer y sentimiento de libertad.

El problema es que escribir para niños casi parece una moda, y en medio de la cantidad de obras que se publican es preciso elegir bien. Aquí ya podemos ver la importancia de la primera columna: poder trabajar desde la selección de libros nos obliga a tener antes una formación literaria.

Por otro lado, no hay que ocultar el lado problemático de la dependencia con las editoriales, cito dos ejemplos, uno nacional que sucedió en marzo y otro de Chile de este mes de abril: en el primer caso observábamos cómo representantes de algunas editoriales transaban la exclusividad de sus libros en los colegios con la condición de dar un porcentaje a los responsables de elegir qué libros deberían usar los alumnos.

Toda oferta es válida en tanto es considerada y trabajada por docentes que sepan no solo elegir, sino también disfrutar y hacer disfrutar esos libros si 
realmente merecen la pena. La otra alternativa es recurrir a los libros usados, algo que no tiene nada de malo y que, mejor aún, nos sirve para trabajar con presupuestos pequeños. Trabajar con las editoriales será efectivo siempre y cuando los libros valgan la pena, es decir, hayan sido elegidos con criterios literarios y tomando en cuenta el interés del grupo de alumnos dejando al docente elegir otras obras si así lo cree conveniente.

En el otro caso una editorial conocida ha provocado todo un debate en Chile por haber incluido en los libros de texto, específicamente de Comunicación para 5..$^{\circ}$ año de primaria, publicidad de algunas marcas de productos comerciales (celulares, aceite, refrescos, entre otros) como herramientas para desarrollar la comprensión. Describo: en la hoja par se ve el afiche publicitario a todo color de un jugo, en la impar vienen las siguientes preguntas: ¿cuál de estas cualidades tiene el producto que se anuncia?, opciones para marcar: menos calorías, sin colorantes, con calcio; ¿cuál de las cualidades que posee el producto te parece más importante?, ¿por qué?... Comprensión lectora un tanto sospechosa, con marketing; para algunos esta es una propuesta original, que acerca la realidad al niño; para otros, simple publicidad disfrazada de texto escolar. En estas situaciones, la presencia clave es la de un docente que sepa acudir a opciones que nazcan de sus propias lecturas y tenga respeto e interés por los alumnos que le toca enseñar antes que por su bolsillo. El gusto lector no se enseña ni se vende, se contagia.

La libertad textual es necesaria no solo por motivos prácticos o económicos, sino también por motivos de efectividad con lo que propone el plan lector, y es que tal como lo señala el crítico italiano Biagio D’Angelo:

La lectura es un acontecimiento porque se constituye por el doble "encuentro" de mundos en contraste: el lector, que va a la búsqueda de las ambigüedades y de las maravillas del mundo que 
le esconde, tal vez, con crueldad, su verdadera cara, y los signos de la estética y del arte, que aproximan los deseos del corazón a la respuesta de la vida. (D’Angelo 2006: 41)

Por tanto, si solo les damos unas opciones limitadas de mundos posibles a nuestros alumnos en el aula, este acontecimiento siempre será sesgado, limitado a otros intereses menos al de ellos. Esta libertad también obliga al docente a conocer más, porque a más opciones más conocimiento de las propuestas que van llegando a la biblioteca del docente. Por su parte, Teresa Colomer señala que «sin demasiadas programaciones escolares, métodos específicos o ejercicios sistemáticos, los niños que están inmersos en un medio rico literariamente progresan muy rápidamente en el dominio de las diferentes posibilidades de estructurar una narración o el ritmo de unos versos» (2005: 205).

A veces, es más fácil que los capacitadores nos den todo masticado, las guías ya elaboradas; pero no deseo que los futuros docentes, al menos 三 los que me toca enseñar, se acostumbren a eso. Libertad sí, pero trabajo también y trabajo responsable.

\section{LA TERCERA Y ÚLTIMA COLUMNA ES CONSIDERAR EL CINE Y LA TELEVISIÓN}

Se hace necesario que los futuros docentes estén familiarizados con el manejo de estos nuevos lenguajes, no por un afán del simple «estar al día», sino porque ayudarán a elegir, criticar o incluso aprovechar los productos audiovisuales que consumen los niños. Es tal como lo dice el dramaturgo Jean Claude Carrière, en diálogo con Umberto Eco, refiriéndose al cine y la televisión: «usted y yo hemos nacido en un siglo que, por primera vez en 
la historia, ha inventado nuevos lenguajes», lenguajes que van más allá del simple ver y que exige educarse, informarse, criticar.

Recuerdo que cuando lancé este tema en el aula una alumna presentó la objeción de que para ella, como docente, no era tan importante el aprender a ver cine y televisión infantil porque le parecía que había otros medios mejor aprovechables como el teatro, ya que, incluso, muchos de sus alumnos no tenían televisión. Le di la razón en parte. Estos medios no son los únicos válidos para usar en un aula; el teatro también es valioso y sería importante que también aprendamos sobre él; pero, dada la presencia e influencia de la televisión o el cine en los niños, significaría taparnos los ojos al no querer comprender estos medios. La tecnología avanza y hoy los pequeños hablan de Ben 10, Los padrinos mágicos, Spiderman ..., tal como muchos de nosotros hablábamos de El llanero solitario, Los Transformers o Candy, y hoy los docentes no podemos hablar nada de los nuevos programas porque nuestro desconocimiento nace al considerar estas producciones como infantiles (aquí un uso negativo de esta palabra).

Si lo pensamos, esta actitud puede ser contradictoria. Creemos conocer y entender el mundo infantil y a los niños por leer revistas de psicología, por publicaciones, cursos y talleres de pedagogía, pero cuando nos toca ir in situ al mundo de ese pequeño, nos consideramos «demasiado adultos» para entrar en él, no es serio ni adecuado. El problema es que hoy más que nunca debemos entrar para proponer nuestra visión, vale decir, hacer que el niño se eduque humanamente, alimente su yo, respete, ame, y en este punto la literatura, sin necesidad de utilizar palabras rebuscados y menos precisas, tiene ese gran atributo: hace vivir. Sé que a todos nos importan los pequeños, somos padres, tíos, tías, hermanos, hermanas, amigos, maestros. Como maestros seguro estamos allí cuando los estudiantes tienen problemas en casa, les tendemos la mano; seguro los apoyamos cuando no entienden 
sus cursos, se esfuerzan por preparar material, se quedan 20 minutos más con el que va más lento... Pero ¿̨por qué no estar también con ellos cuando ríen, cuando se emocionan con el último capítulo de su dibujo o serie favorita? Intentémoslo. Nuestro narrador Jorge Eslava confesaba al público asistente a su charla en el I Congreso internacional de Literatura Infantil y Juvenil que él se impactó de la narrativa del dibujo animado Los supercampeones, por su manejo del tiempo, por la atracción que ejercía en su hijo y nos conminaba a tener esa actitud de niños: curiosos y atentos frente a estas producciones.

Alguien preguntará: «¿Qué tienen de literatura estas producciones?». La respuesta está en el núcleo de esos dibujos o películas. Estas encierran y atraen por una historia, una narración, que casi siempre los niños cuentan con ojos iluminados. Aprovechémosla, el soporte puede haber variado, pero el contenido sigue siendo el mismo: «un héroe», «algo o alguien a quién defender», «un enemigo»...; en suma, relatos para entretener.

Otro motivo lo señala Flavia Propper en su libro La era de los superniños: «los mensajes, personajes, expresiones e imágenes de la televisión forman parte de la socialización de los niños y jóvenes [...] los niños de las generaciones actuales viven una "infancia mediática" [...] por eso resulta primordial indagar los contenidos, personajes y valores que transmiten los programas televisivos» (2007: 14).

En este sentido, el acercamiento al cine, a la televisión no es superfluo en la formación del futuro docente, se une a la dimensión literaria por una línea narrativa que es hija de los juglares, de la oralidad y que hoy ha pasado a lo multimedia, y que, como toda nueva técnica requiere un nuevo lenguaje, es necesario conocer el lenguaje con el que narra para poder saber manejar y valorar las obras que produce.

He planteado estas tres columnas como un aporte a la discusión sobre la literatura infantil en las facultades de Educación: la importancia 
EL CURSO DE LITERATURA INFANTIL Y JUVENIL EN LOS PROGRAMAS UNIVERSITARIOS DE EDUCACIÓN

de la literatura, formarnos en ella antes que en técnicas; lograr que nuestros futuros docentes se nutran de tantas obras bellas y construyan su propio canon. De esta forma podrán trabajar con sus alumnos escuchándolos, compartiendo con ellos lo mismo que a ellos los hizo emocionar, reír, llorar, y al final dialogar con el niño, aprovechando tanto lo que lee como lo que ve, poder discutir, aconsejar, compartir sobre esos mundos fantásticos que le presentan los libros y la pantalla: héroes, princesas, robots, de niños como ellos y de adultos como nosotros. Solo así se sentirán respetados y tomados en cuenta, y el resultado será que, quizás, vean que en el aula les brinda un libro como una mano amiga, cercana, cordial, y que su lectura sea tanto participativa como personal, enriquecedora y que contagie. Ojalá la próxima generación de docentes cumpla con este anhelo. 


\section{BIBLIOGRAFÍA}

Colomer, Teresa

2005 «El desenlace de los cuentos como ejemplos de las funciones de la literatura infantil y juvenil». Revista de Educación, núm. extraordinario, pp. 203-216.

D’Angelo, Biagio

2006 «Para una educación a la lectura de los clásicas». Riesgo de Educar, año 1, N. 2, pp. 31-41.

DoMech, Carmen et ál.

2004 Animación a la lectura.¿Cuántos cuentos cuentas tú? Madrid: Popular.

Eco, Umberto y Jean Claude Carrière

Є2010 Nadie Acabará con los libros. Buenos Aires: Lumen.

: Propper, Flavia

2001 La era de los superniños. Buenos Aires: Alfagrama.

Zilberman, Regina

2006 «El estatuto de la literatura infantil». Cuadernos Literarios, año III, N.6: Letritas, pp. 17-38.

\section{Notas}

Sobre el caso de los textos escolares en Perú puede verse la web de Panamericana Televisión (reportaje en video): <www.panamericana.pe/noticias/82023>. 
EL CURSO DE LITERATURA INFANTIL Y JUVENIL EN LOS PROGRAMAS UNIVERSITARIOS DE EDUCACIÓN

Sobre el caso de los textos escolares en Chile puede verse la web del diario español La información: <http://noticias.lainformacion.com/educacion/ ensenanza-y-aprendizaje/los-libros-de-texto-de-santillana-en-chileincluyen-anuncios publicitarios_np6qmH2SGo03qR2llorK32/>. 